\title{
Men's management of urinary incontinence in daily living: implications for practice
}

\author{
Shona McKenzie, Winsome St John, Marianne Wallis and Susan Griffiths
}

International Journal of Urological Nursing 2013; Vol 7 No 1: 43-52 doi: 10.1111/j.1749-771X.2012.01167.x RESEARCH PAPER

\author{
Authors: \\ S McKenzie, BSc, MN, MCHP, Department of Urology, Royal Brisbane and Women's Hospital, \\ Brisbane, Queensland, Australia; \\ W St John, RN, PhD, Population and Social Health Research Program, Griffith Health Institute, \\ Griffith University, Gold Coast, Queensland, Australia; \\ M Wallis, RN, PhD, Research Centre for Clinical Practice Innovation,Griffith University and Gold \\ Coast Health Services District, Gold Coast, Queensland, Australia; \\ S Griffiths, BA, Research Centre for Clinical Practice Innovation, Griffith University, Gold Coast, \\ Queensland, Australia
}

Address for correspondence: Shona McKenzie, Department of Urology, Royal Brisbane and Women's Hospital, Brisbane, Queensland, Australia

E-mail: shona_mckenzie@health.qld.gov.au

\begin{abstract}
Many men develop urinary incontinence following prostate disease or surgery. Men with urinary incontinence use strategies to manage urinary incontinence in their daily lives, often with minimal assistance from health professionals. Much of the available information and advice offered to men about daily-living management of urinary incontinence have been adapted from information relating to management difficulties experienced by women. This study explored strategies used by communitydwelling men to manage urinary incontinence in their daily lives. Men with self-reported urinary incontinence were recruited from clinical and non-clinical settings. A researcher-developed survey was used to identify type, severity and duration of urinary incontinence, and the strategies men used to manage urinary incontinence in daily living. Sixty-one items, grouped according to functional strategies, asked how often each strategy was used to manage urinary incontinence. A response rate of $66 \%$ was achieved with 103 men completing a survey. The findings of this study can be used by urology nurses to ensure continence education for men with urinary incontinence addresses areas that are of most importance, as well addressing their specific needs.
\end{abstract}

\section{Key words: Community $\cdot$ Continence $\cdot$ Men $\cdot$ Men's health $\cdot$ Self-management $\cdot$ Urinary incontinence}

\section{WHAT IS KNOWN ABOUT THIS TOPIC}

- Urinary incontinence is a common problem that has a major impact on the physical, emotional and social well-being of men.

- To achieve social continence people with urinary incontinence use a wide range of management strategies including toileting, fluids, body

- care, social life and daily routines.

WHAT THIS PAPER ADDS

- This paper provides information regarding self management strategies commonly used by men to manage their urinary incontinence in

- everyday living.

- Information to guide urology nurses in the development of continence education for their male patients that addresses their specific needs. 


\section{INTRODUCTION}

This survey study explored strategies used by community-dwelling men to manage urinary incontinence (UI) in everyday living.

\section{BACKGROUND}

In Australia, an estimated 4.16 million people experience $\mathrm{UI}$, and of those approximately $20 \%$ are men (Deloitte Access Economics, 2011). The prevalence rate is projected to rise with projected figures for men estimated to be almost 1.2 million in 2030 (Australian Institute of Health and Welfare (AlHW), 2006; Deloitte Access Economics, 2011). The main cause of UI in men is age-related lower urinary tract symptoms (LUTS) exacerbated by declining functional ability. LUTS describes a collection of urinary symptoms that occur in men and women principally as part of the ageing process, such as decreased bladder capacity, increased urgency, increased post void residual and bladder outlet obstruction in men (DuBeau, 2002). Older men often experience LUTS in association with benign prostatic hyperplasia (BPH) (Barry, 2001) sometimes leading to surgery involving partial prostatectomy. In cases of prostate cancer, men are likely to be offered radical prostatectomy, which can leave men incontinent of urine, at least in the short term (Van Kampen et al. (2000). Some men find their urinary symptoms decrease in response to treatments, while others do not experience an improvement, and in some cases the condition worsens over time. Finding the strategies to manage $\mathrm{Ul}$ in day-to-day life, therefore, becomes an important priority for men seeking to manage this temporary or chronic condition. The mechanics of how $\mathrm{UI}$ is managed may vary, but the rationale of being in control in order to maintain Men's management of urinary incontinence a normal lifestyle and social identity remains the underlying theme of continence management (Skoner and Haylor, 1993; Paterson, 2000; Eastwood et al., 2002). The way UI is managed is influenced by individuals' functional and cognitive ability, the severity of the UI (Engberg et al., 1995; Miller et al., 2003), type of UI (Lam et al., 1992; Engberg et al., 1995), age (Miller et al., 2003) and gender (Herzog et al. 1989; Brocklehurst, 1993). It is also influenced by an individual's normal daily patterns and contexts, for example, whether the person is mainly at home or at work (Peake and Manderson, 2003).

The literature reveals a wide range of management strategies used by people with $\mathrm{UI}$ to maintain continence. Although each person will tailor management to their own needs, there are common strategies categorized as: fluids, toileting, body care, social life, daily routine, physical activity, skin care and pads and aids St John et al. (2010). For example, men attempting to normalize UI will often change their fluid intake (Johnson et al., 2000; Koch et al., 2000) and restrict activities (Mitteness, 1987; Hrisanfow and H"agglund, 2011) to prevent an unanticipated UI episode when out in public. However, the unpredictable nature of $\mathrm{UI}$ and an overriding concern to continue life as normal means that not all strategies work for everyone and some strategies, although effective, can be deleterious in other ways. This study explored the strategies community-dwelling men use to manage $\mathrm{UI}$ in everyday living according to functional categories. This research provides health professionals with a comprehensive picture of the ways men manage and, therefore, an evidence base to inform their clinical advice. For the purposes of this study, daily-living management was defined as the strategies used to integrate UI into daily life, rather than strategies designed to treat or cure it (Locher et al., 2002).

\section{PROJECT AIMS/DESIGN}

This descriptive study used a survey design to identify the type and frequency of management strategies used by community-dwelling men to manage $U I$ in daily life. This study is part of a larger mixed methods project investigating daily-living management of UI, which included women.

\section{SAMPLE}

Criteria for selection into the study included: being aged over 18 years; experiencing UI; living independently in the community (that is not dependent on a carer for toileting) and speaking, reading and writing ability in English sufficient to complete the questionnaire. Those with cognitive/intellectual impairment, who were dependent on others for toileting and/or receiving institutionalized care, were excluded, because they would not have the ability to self-manage. 
Ethical approval for the study was gained from the university and participating health care agencies. Participants were recruited from South-East Queensland and Northern New South Wales, Australia. Health professionals from public and privately funded continence clinics provided clients with an explanation of the project, gained consent and supplied the questionnaire and a reply-paid envelope. To access men who were not using health agencies, advertisements and stories were run in a number of community papers, which invited men with UI to contact the project coordinator. Men recruited via the media were provided with information about the study, briefly assessed over the phone to determine their eligibility and sent detailed information about the project, a consent form, the questionnaire and a reply-paid envelope for return by post.

\section{DATA COLLECTION}

Although many tools were found that examined the impact of UI, few investigated the breadth of strategies people used to manage UI in their daily lives (Talbot, 1994). As a consequence, the research team developed a questionnaire to meet the needs of the study. Items were based on a comprehensive review of the research literature (St John et al., 2010). Sixty-one items with Likert-type responses of 'never/rarely', 'sometimes' and 'often' were listed under functional headings: Fluids, Toileting, Pads and aids, Social strategies, Daily routines, Hygiene and body care and Physical activity and exercise. In addition to the strategy items, the questionnaire sought information on type and severity of incontinence using a tool developed by Coyne and associates Coyne et al. (2003) and the incontinence severity index (Sandvik et al., 1993). Additional questions were developed to identify those men experiencing mainly dribble UI. In situations where the symptoms were not clearly defined an expert continence nurse specialist was consulted to make a clinical decision regarding the main type of UI based on questionnaire responses. Finally, questions related to demographic characteristics and normal physical activity were included, and two 10-point visual analogue scales were used to measure perceived 'level of interference' and 'ability to manage'. The questionnaire was reviewed by a statistician and two continence nurse specialists and piloted with nine people living with UI who completed the questionnaire and an accompanying evaluation form. The Men's management of urinary incontinence questionnaire was revised to make it shorter and simpler, and again piloted with a further three people living with UI.

\section{DATA ANALYSIS}

Survey data were entered into SPSS version 12.0.1. Using the formula provided, scores were calculated to determine the participants' type and severity of UI. Descriptive statistics were generated to provide an overview of the demographic and clinical characteristics of the sample. To identify the most commonly used strategies, percentages were calculated for men who reported using each strategy at least 'sometimes' or 'often' and strategies were ranked within each functional category.

\section{RESULTS}

One hundred and three men completed the questionnaire. The proportion of men recruited from clinical (48.5\%) and non-clinical (51.5\%) environments was almost equal. The men participating in the study represented a range of socioeconomic profiles and clinical presentations (see Table 1). The average age of the men was 69 years and the average time they had experienced UI was 2 years with $44 \%$ experiencing UI for more than 3 years. Most men lived with their partner or spouse $(72 \%)$ and most were no longer in paid employment $(71 \%)$. The majority of men in this sample were educated to year 12 or had a technical or bachelor qualification (67\%) and most reported their day-today activity as encompassing light to heavy physical work (70\%). In this sample, $78 \%$ of men were categorized as having urge or mixed $\mathrm{UI}$ and $72 \%$ reported their level of severity as moderate. Overall, men considered they managed reasonably well, with $61 \%$ of participants rating their 'ability to manage' $\mathrm{Ul}$ at seven or greater on the 10-point scale. The mean rating for perceived 'level of interference' was four, indicating a degree of interference; however, $32 \%$ of men rated interference as a seven or above.

\section{Fluids, toileting and pads and aids}

Strategies used to manage $\mathrm{UI}$ in daily living related to fluids, toileting and pads and aids are outlined in Table 2. Of the 61 items, the 2 most commonly used practices by men to manage their incontinence were toileting strategies. Almost $90 \%$ of men got up at night to urinate and $91 \%$ went to 
the toilet as an immediate response to urge. Five toileting practices centred around the proximity and knowledge of toilet locations with $76 \%$ of men actively locating toilets when arriving at an unfamiliar place and $50 \%$ of men knowing the location of toilets before they leave home. Regular toileting was another well-used strategy adopted by $58 \%$ of men who kept their bladder empty when out. Strategies that involved avoiding or reducing fluids were adopted by $51-60 \%$ of men in this sample. Practices that targeted limiting alcohol and caffeinated drinks more specifically were used by $43-48 \%$ of men. The data were similar whether the fluid-limiting strategies were targeted to manage UI outside the home or otherwise. Fifty-six percent of men chose to use pads and/or aids to manage $\mathrm{UI}$ and $53 \%$ were discriminating in their choice of product to enhance protection. Only $17 \%$ of men used different products depending on whether they were out or at home; however, $38 \%$ of men did select their pads or aids based on the type of activities in which they engaged.

\section{Social strategies and routines}

Social strategies and routines used to manage $\mathrm{UI}$ in daily living are outlined in Table 3 . The most commonly used social and routine practice was making leaking a normal part of everyday life, which was adopted by $74 \%$ of men. The majority of men also sought knowledge and support through: learning as much as they can about $\mathrm{UI}(70 \%)$, seeing health professionals $(61 \%)$ and talking about the condition with people close to them to engage their understanding (60\%). While most men sought help from a health professional, only $41 \%$ of men sought help from close family or friends and $57 \%$ intentionally kept accidents a secret from those close to them. Another cognitive strategy was used to redirect attention from $\mathrm{UI}$ accidents by using humour or positive thinking, which was adopted by $60 \%$ of the men. While management strategies that limited travel, socializing and new relationships were less common, one-quarter to more than one-third of men reported adopting these strategies in daily life. Most of the men (57\%) reported developing a routine to reduce the chance of leaking in public. Some routines were specific to activity outside the home and involved: avoiding situations where access to a toilet was problematic (55\%); taking spare pads/aids $(50 \%)$ or a change of clothes/underwear (44\%) whenever out; and, modifying the timing or type of medication before leaving home $(18 \%)$. Precautionary routines were extended to staying at home in general (27\%) or staying at home if conditions, such as poor health or cold weather, increased the probability of leaking $(35 \%)$. Close to half of men $(47 \%)$ reported that, in general, they avoid situations where they were likely to leak.

\section{Hygiene, body care, cleaning, physical activity and exercise}

Hygiene, body care, cleaning, physical activity and exercise strategies used to manage $\mathrm{UI}$ in daily living are outlined in Table 4 . Almost $80 \%$ of men reported that keeping their bowels regular was an important strategy for managing UI. While modifying their diet was used by almost half of the sample $(47 \%)$, fewer men selected losing weight as a management strategy $(21 \%)$. Strategies to manage odour and skin care were adopted by men to varying degrees. Many men reported regularly washing clothes and bedding (69\%), while less reported having more showers than usual $(46 \%)$, changing pads frequently $(45 \%)$, using deodorisers/perfume $(42 \%)$, creams $(31 \%)$ and skin wipes $(21 \%)$. Strategies that emphasized the protection and cleaning of clothes and home furnishings were used by at least one-quarter of the men, indeed purchasing easy-care clothing was a strategy adopted by $50 \%$ of men. While less common, strategies attending to home care were used by $25-29 \%$ of men, for example, protecting soft furnishings and using protective aids for bedding. Additionally, one-quarter of men used a special bag to manage the disposal of pads. While men in this sample showed some adaptations in relation to physical activity and exercise, the most prominent strategy was to stop doing activities that made them leak (64\%). Daily-living strategies that involved continuing activity participation but with some changes were less common, with $40 \%$ of men planning activities for when they were less likely to leak and $25 \%$ of men modifying activities in which they participated. Pelvic floor exercises (PFEs) were incorporated into some men's management of UI: $27 \%$ of men did PFEs if they were in danger of leaking due to coughing or lifting, for example; and $15 \%$ of men did PFEs before engaging in a particular activity. Some men used strategies to manage $\mathrm{UI}$ in the context of sexual activity. Urinating before and/or after sex was used by $38 \%$ of men and one-third of men used different positions for sex. A number of men avoided sexual intercourse or orgasm altogether (13\%).

\section{DISCUSSION}


It is clear that managing, for people with $\mathrm{UI}$, is about selecting strategies that contribute to maintaining a normal lifestyle. A number of papers report the importance of 'normalizing' for women with UI (Milne and Moore, 2006; Hagglund and Ahlstrom, 2007) and the findings of this study suggest that this cognitive strategy is also used by men. Most of the men sometimes or often adopted the strategy to 'make managing leaking a normal part of everyday life', suggesting that many men use strategies that adapt as much as possible to their lifestyle.

Fluids, toileting and using pads and aids were important strategies for normalizing UI. However, while adaptive and 'normalizing' strategies may be effective in the short term, some may hinder recovery or worsen a bladder condition over time. For example, at least half of the men in this study reduced or avoided fluids as a way of managing leaking. This behaviour runs counter to current advice to consume 1.5-2 $\mathrm{L}$ of fluid a day. Nevertheless, these findings are consistent with the findings from other studies that have found that people who experience Ul frequently modify or manipulate their fluid intake (Herzog et al., 1989). Johnson et al. (2000) identified that men with UI tend to restrict their fluid intake when going out or before bedtime and Koch et al. (2000) found that men stopped drinking in the hours before leaving home to ensure they did not need to void before reaching work. Interestingly, $49 \%$ of men in this study did not avoid fluids when out, suggesting that a moderate proportion of men with UI continue their fluid intake as normal when at work, travelling or in social situations. Similarly, while $43-48 \%$ of men reported reducing or avoiding alcohol and caffeinated drinks, over half of the men did not modify their consumption of these drinks. Data from this study confirm that toileting is a predominant concern for men with participants using a range of toileting strategies to manage their UI. Many researchers have identified that people with UI are acutely conscious of the accessibility of and closeness to a toilet, potentially scheduling activities according to their proximity to toilets, always being aware of their location and developing a cognitive map of toilets in their area and neighbourhood (Ashworth and Hagan, 1993; Thomas and Morse, 1991; Skoner, 1994; Mitteness and Barker, 1995). Strategies focused on the location and proximity of toilets when away from home were common, with three-quarters of men prioritizing locating a toilet when they first arrived at a new destination and $35 \%$ of men planned outings that were close to toilets. Few participants in this study practised deferred voiding techniques, with $91 \%$ of men going to the toilet as soon as they felt the urge. A majority of participants engaged in toileting strategies that required longer term planning, such as organizing their bedrooms close to the toilet, knowing where all the toilets are before going out and planning outings close to toilets. Other studies have described strategies including scheduled or regular urination (Mitteness, 1987; Herzog et al., 1989; Palmer et al., 2003), going to the toilet immediately on arriving somewhere (Mitteness, 1987) and going to the toilet immediately the need to urinate is felt (Brown et al., 2000).

Health professionals often recommend continence aids as an adjunct to other treatments, enabling a person to maintain social continence. The objective of continence products such as pads or external catheters is to contain all urine leakage and prevent leakage onto outer clothing (Gallo and Staskin, 1997). Although researchers have concluded that men are less likely to use incontinence pads than women (Johnson et al., 2000; Hrisanfow and H"agglund, 2011) and in some cases find pad use stigmatizing (Milne and Moore, 2006); 56\% of men in this sample adopted this strategy as a way to manage UI. It is possible better design in pads is affecting men's choices, although we did not ask about this. Of the men using pads in this study, some were also mindful of selecting a product most likely to protect them when out of the house and a smaller proportion when engaging in specific activities.

The survey data from this study present a complex picture of men both maintaining and restricting participation in social life. Overall, many men sought to ensure their social activities were not affected by UI; over $63 \%$ of men did not limit possibilities for travel, socializing or new relationships. These findings are in line with a study by Thomas and Morse (1991) which found that $83 \%$ of the participants did not significantly reduce activities outside of the home, and determined that UI would not keep them at home. Another motivating factor may be the symbolic association of leaking with dependence, especially for people in later life (Mitteness and Barker, 1995).

Participants used a combination of strategies to keep things as normal as possible. Over two-thirds of men said they learned as much as possible about UI with many seeking help and support from health professionals and close family and friends. Although $60 \%$ of participants used humour and positive thinking after an experience of $\mathrm{UI}$, it is clear that secrecy and concealment are major preoccupations for those experiencing UI. Our findings are consistent with previous studies showing that people with 
UI control information about their UI carefully, only revealing their problem to very close family and friends (Mitteness and Barker, 1995), and that some maintain UI as a secret even from close family and co-workers (Ashworth and Hagan, 1993). This finding seems paradoxical when coupled with the equally common strategy for men in our study to talk about the condition with people close to them. Perhaps these findings reflect the conflicting need for control of information and a safe place for seeking understanding and support, while also minimizing potential embarrassment about having an accident.

Being prepared and developing routines were predominant features of participants' strategies to maintain social participation. Over half of the men indicated that they developed a routine to reduce the chance of leaking in public, suggesting that many tailored their daily-living management to suit their particular situation. Many routines designed to reduce the likelihood of $\mathrm{Ul}$ in public or to manage an accident, such as taking extra pads or clothing when out, were consistent with the types of strategies used by women (Fitzgerald et al., 2002; Diokno et al., 2004). Maliski et al. (2001) identified that people with incontinence experience self-mastery and control over their UI when they can establish an effective management routine.

Interestingly, while most men in this study did not limit travel or socializing in general, around half of them reported avoiding situations where they could not get to a toilet easily $(55 \%)$ or where they might be likely to leak (47\%). Indeed $35 \%$ of men reported that they would stay at home at times when they were more likely to leak and $27 \%$ said they stayed at home without precondition. These findings are consistent with other research findings that indicate people often restrict social activities to manage their UI (Lam et al., 1992; Adams et al., 1994; Engberg et al., 1995; Abrams et al., 2000; Koch et al., 2000; Paterson, 2000; Lose, 2005), and limit social activity to private places, such as home (Mitteness and Barker, 1995), sometimes to the extent of isolation (Mitteness, 1987). Although the majority of men in our study did not limit social engagement, it was concerning that at least a quarter of the men in this sample stayed at home, avoided new relationships and socializing or travel in general. This suggests that men may be amenable to support and ideas about daily-living continence management to maintain social continence.

Body care and hygiene strategies were predominantly used to maintain social continence and reduce the impact of incontinence on normal daily activities, rather than reduce the risk of a UI episode. These included strategies such as regulating bowels, selecting appropriate clothing, skin care and weight loss. Maintaining regular bowel actions is recommended by health professionals to reduce the impact of incontinence (Norton, 1996; Assad, 2000; Getliffe and Dolman, 2003) based on a link between constipation and $\mathrm{UI}$ in women Chiarelli et al. (1999), although this association has not been demonstrated in men (Ueda et al., 2000). Despite this, 79\% of the men in this study stated that they used this strategy. Other studies also identify men with $\mathrm{UI}$ wearing dark coloured clothing as a strategy to conceal accidents (Palmer et al., 2003) and Pateman and Johnson (2000). Pateman and Johnson (2000) also describe men's fear of developing an 'old men's smell' as a consequence of UI. A moderate proportion of men in this study reported using strategies to conceal wet patches or odour; $42 \%$ of the men wore dark coloured clothing; $46 \%$ had more showers than usual; $45 \%$ changed pads frequently to avoid the smell of urine and, $42 \%$ used perfumes and deodorizers. Hunskaar and Sandvik (1993) reported that skin irritation was a management problem for $12 \%$ of participants. In this study, $31 \%$ of men used creams to protect their skin and $21 \%$ used skin wipes, suggesting that skin irritation may have presented a more of a problem to participants in this study. The management of $\mathrm{UI}$ at home, while potentially less challenging, remained an issue to some participants in the sample as indicated by $29 \%$ of men making sure their floors were easy to clean and using protective aids for their bedding. One-quarter of men also sought to protect their soft furnishings at home.

The importance of maintaining a program of regular exercise cannot be overstated. Participation in activity and exercise improves physical and cognitive function as well as improving overall health and wellbeing, notwithstanding the added value of social connections. In this study, $64 \%$ of men reported ceasing activities that can cause leakage, such as jogging or dancing. Thompson and Smith (2002) identified that people with UI do not necessarily stop activities, preferring to choose strategies that allow them to continue their normal lifestyle. In this study, there is evidence that men prioritize living life as usual when managing $\mathrm{UI}$; therefore, discontinuing activity as a management strategy seems contradictory to this aim. The alternative to not exercising is to modify activities to reduce the risk of leaking; $25 \%$ of men in this study used this strategy and $40 \%$ of men planned their activities for times when they were less likely to leak. It remains significant, however, that a large proportion of men 
stopped their participation in activities altogether. Indeed, this strategy was the eighth most popular strategy of the 61 items presented in the survey.

PFEs are recommended for men following prostatectomy and as a method for improving UI (Van Kampen et al., 2000; Lin et al., 2011). In this study, $27 \%$ of men tightened their pelvic floor muscles if in danger of leaking and $15 \%$ of men performed these exercises prior to particular occasions. Men also used strategies to reduce the risk of incontinence during sex. Indeed, strategies to maintain sexual activity were more

popular than strategies to maintain activity or exercise in general; $38 \%$ of men urinated before and or after sex and $33 \%$ of men used different positions for sex. Although only $13 \%$ of men avoided having sexual intercourse or orgasm, identifying whether clients use this strategy is important because of the impact it could have on a man and his relationships.

There were limitations to this study. While a non-probability sample was used, the men were recruited from both clinical and non-clinical settings and showed a spread of demographic and continence characteristics. It is likely that therefore the men in this study will reflect some elements of the wider population of Australian men managing $\mathrm{UI}$ in their daily life.

\section{CONCLUSION}

This study showed that the men in this study used many daily-living strategies to manage UI, which were generally focused on achieving social continence and keeping it a secret. A wide range of individually tailored strategies were used including: toileting, fluids, pads and aids, social strategies, routines, hygiene and body care, and modification to physical activity. Strategies chosen reflected the personal and social context and needs of the individual. The results of this study shed light on the daily living strategies men use as the struggle to maintain social continence. Because many men may not discuss UI with even close family and friends, nurses may sometimes be the only source of psychological support and practical advice. In addition to clinical assessment and care, the results of this study suggest that nurses have an important role in providing assessment and advice about how men can manage $\mathrm{UI}$ in their daily lives. These findings could inform appropriate client assessment, discussion and advice, particularly generating ideas about how UI could be managed better, and the longer term risks associated with some commonly used strategies. 


\section{REFERENCES}

Abrams P, KelleherC,Kerr L,RogersR. (2000). Overactive bladder significantly affects quality of life. The American Journal of Managed Care; 6 (11 supp): S533-S590.

Adams C, Lorish C, Cushing C, Willis E, Jackson J, Walter J. (1994). Anatomical urinary stress incontinence in women with rheumatoid arthritis: its frequency and coping strategies. Arthritis Care and Research; 7 (2): 97-103.

Ashworth PD, Hagan MT. (1993). The meaning of incontinence: a qualitative study of non-geriatric urinary incontinence sufferers. Journal of Advanced Nursing; 18 (9): 1415-1423.

Assad L. (2000). Urinary incontinence in older men. Topics in Geriatric Rehabilitation; 16 (1): 33-53.

Australian Institute of Health and Welfare (2006), Australian Incontinence Data Analysis and Development, Australian Institute of Health and Welfare; Canberra: AIHW cat. no. DIS44.

Barry MJ. (2001). Evaluation of symptoms and quality of life in men with benign prostatic hyperplasia. Urology; 58 (6 Suppl 1): 25-32.

Brocklehurst JC. (1993). Urinary incontinence in the community: analysis of a MORI poll. BMJ; 306 (6881): 832-834.

Brown J, Vittinghoff E, Wyman J, Stone K, Nevitt M, Ensrud K, Grady D. (2000). Urinary incontinence: does it increase risk of falls and fractures? Journal of the American Geriatrics Society; 48 (7): 721-725.

Chiarelli P, Brown W, McElduff P. (1999). Leaking urine: prevalence and associated factors in Australian women. Neurourology and Urodynamics; 18: 567-577.

Coyne KS, Zhou Z, Thompson C, Versi E. (2003). The impact on health-related quality of life of stress, urge and mixed urinary incontinence. BJU International; 92 (7): 731-735.

Deloitte Access Economics. (2011). The Economic Impact of Incontinence in Australia. Melbourne: Continence Foundation of Australia.

Diokno A, Burgio K, Fultz N, Kinchen K, Obenchain R, Bump R. (2004). Medial and self-care practices reported by women with urinary incontinence. The American Journal of Managed Care; 10 (2): 69-78.

DuBeau CE. (2002). The continuum of urinary incontinence in an aging population. Geriatrics; 57 (Suppl 1): 12-17.

Eastwood S, Kralik D, Koch T. (2002). Compromising and containing: self-management strategies used by men and women who live with multiple sclerosis and urinary incontinence. The Australian Journal of Holistic Nursing; 9 (1): 33-43.

Engberg SJ, McDowell BJ, Burgio KL, Watson JE, Belle S. (1995). Self-care behaviors of older womenwith urinary incontinence. Journal of Gerontological Nursing; 21 (8): 7-14.

Fitzgerald S, Palmer M, Kirkland V, Robinson L. (2002). The impact of urinary incontinence in working women: a study in a production facility. Women \& Health; 35 (1): 1-16.

Gallo M, Staskin DR. (1997). Patient satisfaction with a reusable undergarment for urinary incontinence. JWOCN; 24 (4): 226-236.

Getliffe K, Dolman M. (2003). Promoting Continence: A Clinical and Research Resource. 2nd edn. Philadelphia: Bailliere Tindall.

Hagglund D, Ahlstrom G. (2007). The meaning of women's experience of living with long-term urinary incontinence is powerlessness. Journal of Clinical Nursing; 16: 1946-1954.

Herzog AR, Fultz NH, Normolle DP, Brock BM, Diokno AC. (1989). Methods used to manage urinary incontinence by older adults in the community. Journal of theAmericanGeriatrics Society; 37 (4): 339-347.

Hrisanfow E, H"agglund D. (2011). The prevalence of urinary incontinence amongwomenandmenwith chronic obstructive pulmonary disease in Sweden. Journal of Clinical Nursing; 20 (13-14): 18951905.

Hunskaar S, Sandvik H. (1993). One hundred and fifty men with urinary incontinence. Scandinavian Journal of Primary Health Care; 11: 193-196.

Johnson TM 2nd, Kincade JE, Bernard SL, Busby-Whitehead J, DeFriese GH. (2000). Self-care practices used by older men and women to manage urinary incontinence: results from the national follow-up survey on self-care and aging. Journal of the American Geriatrics Society; 48 (8): 894-902.

Koch T, Kralik D, Kelly S. (2000). We just don't talk about it: men living with urinary incontinence and multiple sclerosis. International Journal of Nursing Practice; 6 (5): 253-260.

Lam GW, Foldspang A, Elving LB, Mommsen S. (1992). Social context, social abstention, and problem recognition correlated with adult female urinary incontinence. Danish Medical Bulletin; 39 (6): 565-570. 
Lin Y, Yang M, Lin V, Yu T, Chiang P. (2011). The effectiveness of pelvic floor exercises on urinary incontinence in radical prostatectomy patients. International Journal of Urological Nursing; 5 (3): $115-122$.

Locher JL, Burgio KL, Goode PS, Roth DL, Rodriguez E. (2002). Effects of age and causal attribution to aging on healthrelated behaviors associated with urinary incontinence in older women. The Gerontologist; 42 (4): 515-521.

Lose G. (2005). The burden of stress urinary incontinence. European Urology Supplements; 4: 5-10.

Maliski SL, Heilemann MV, McCorkle R. (2001). Mastery of postprostatectomy incontinence and impotence: his work, her work, our work. Oncology Nursing Forum; 28 (6): 985-992.

Miller YD, Brown WJ, Smith N, Chiarelli P. (2003). Managing urinary incontinence across the lifespan. International Journal of Behavioral Medicine; 10 (2): 143-161.

Milne JL, Moore KN. (2006). Factors impacting self-care for urinary incontinence. Urologic Nursing; 26 (1): 41-52.

Mitteness LS. (1987). The management of urinary incontinence by community-living elderly. The Gerontologist; 27 (2): 185-193.

Mitteness LS, Barker JC. (1995). Stigmatizing a "normal" condition: urinary incontinence in late life. Medical Anthropology Quarterly; 9 (2): 188-210.

Norton C. (1996). Nursing for Continence. 2nd edn. Beconsfield: Beaconsfiled Publishers Ltd.

Palmer MH, Fogarty LA, Somerfield MR, Powel LL. (2003). Incontinence after prostatectomy: coping with incontinence after prostate cancer surgery. Oncology Nursing Forum; 30 (2 part 1): 229_ 238.

Pateman B, Johnson M. (2000).Men's lived experiences following transurethral prostatectomy for benign prostatic hypertrophy. Journal of Advanced Nursing; 31 (1): 51-58.

Paterson J. (2000). Stigma associated with postprostatectomy urinary incontinence. JWOCN; 27 (3): 168-173.

Peake S,Manderson L. (2003). The constraints of a normal life: the management of urinary incontinence by middle agedwomen. Women \& Health; 37 (3): 37-51.

Sandvik H, Hunskaar S, Seim A, Hermstad R, Vanvik A, Bratt H. (1993). Validation of a severity index in female urinary incontinence and its implementation in an epidemiological survey. Journal of Epidemiology and Community Health; 47 (6): 497-499.

Skoner MM, HaylorMJ. (1993).Managing incontinence: Women's normalizing strategies. Health Care for Women International; 14 (6): 549-560.

Skoner M. (1994). Self-management of urinary incontinence among women 31-50 years of age. Rehabil Nurse; 19 (6): 339-343, 347.

St John W, Wallis M, Griffiths S, McKenzie S. (2010). Daily living management of urinary incontinence: A synthesis of the literature. JWOCN; 37 (1): 80-90.

Talbot LA. (1994). Coping with urinary incontinence: development and testing of a scale. Nursing Diagnosis; 5 (3): 127-132.

Thomas AM, Morse JM. (1991). Managing urinary incontinence with self-care practices. Journal of Gerontological Nursing; 17 (6): 9-14.

Thompson D, Smith D. (2002). Continence nursing: a whole person approach. Holistic Nursing Practice; 16 (2): 14-31.

Ueda T, Tamaki M, Kageyama S, Yoshimura N, Yoshida O. (2000). Urinary incontinence among community-dwelling people aged 40 years or older in Japan: prevalence, risk factors, knowledge and self-perception. International Journal of Urology; 7 (3): 95-103.

Van Kampen M, De Weerdt W, Van Poppel H, De Ridder D, Fey H, Bacrt L. (2000). Effect of pelvic re-education on duration and degree of incontinence after radical prostatectomy a randomised trial. 
Table 1: Demographic and continence characteristics of men with UI $(n=103)$

\begin{tabular}{|c|c|}
\hline \multicolumn{2}{|l|}{ Demographic Characteristics } \\
\hline Age: years & $\mathrm{n}=99$ \\
\hline Minimum - Maximum & $34-92$ \\
\hline Mean(SD) & $69.3(10.97)$ \\
\hline Highest level of education: n(\%) & $n=100$ \\
\hline Less than year 12 & $25(25.0)$ \\
\hline Year 12 & $21(21.0)$ \\
\hline TAFE/Trade & $21(21.0)$ \\
\hline University degree & $25(25.0)$ \\
\hline Other & $8(8.0)$ \\
\hline Living arrangements: $\mathrm{n}(\%)$ & $n=103$ \\
\hline Lives with spouse/other & $74(71.8)$ \\
\hline Lives alone & $29(28.2)$ \\
\hline Occupation: $n(\%)$ & $\mathrm{n}=102$ \\
\hline Not in paid employment & $72(70.6)$ \\
\hline Non-professional & $14(13.7)$ \\
\hline Professional & $16(15.7)$ \\
\hline Level of physical activity day to day: $n(\%)$ & $\mathrm{n}=83$ \\
\hline Sitting & $25(30.1)$ \\
\hline Standing - light physical work & $37(44.6)$ \\
\hline Moderate - heavy physical work & $21(25.3)$ \\
\hline \multicolumn{2}{|l|}{ Continence Characteristics } \\
\hline Severity of incontinence: $n(\%)$ & $n=102$ \\
\hline Slight & $13(12.7)$ \\
\hline Moderate & $73(71.6)$ \\
\hline Severe & $16(15.7)$ \\
\hline Type of incontinence: $n(\%)$ & $n=103$ \\
\hline Stress & 14(13.6) \\
\hline Urge & $45(43.7)$ \\
\hline Mixed & $35(34.0)$ \\
\hline Dribble & $9(8.7)$ \\
\hline Duration of UI: Year & $\mathrm{n}=98$ \\
\hline Minimum - Maximum & 1 month - 50 yrs \\
\hline Median (IQR) & $2(5.5)$ \\
\hline \multicolumn{2}{|c|}{ Level of Interference rating (0-10) Higher = more interference } \\
\hline Minimum - Maximum & $0-10$ \\
\hline Mean(SD) & $4.14(3.39)$ \\
\hline \multicolumn{2}{|c|}{ Ability to Manage rating (0-10) Higher = better able to manage } \\
\hline Minimum - Maximum & $0-10$ \\
\hline Mean(SD) & $6.89(2.99)$ \\
\hline
\end{tabular}

General Note: All data expressed as n(\%) except for Age (Mean and SD) and Duration of UI (Median and IQR), which have a skewed distribution 
Table 2: $\quad$ Ranked daily-living strategies for managing urinary incontinence: Fluids, toileting and pads

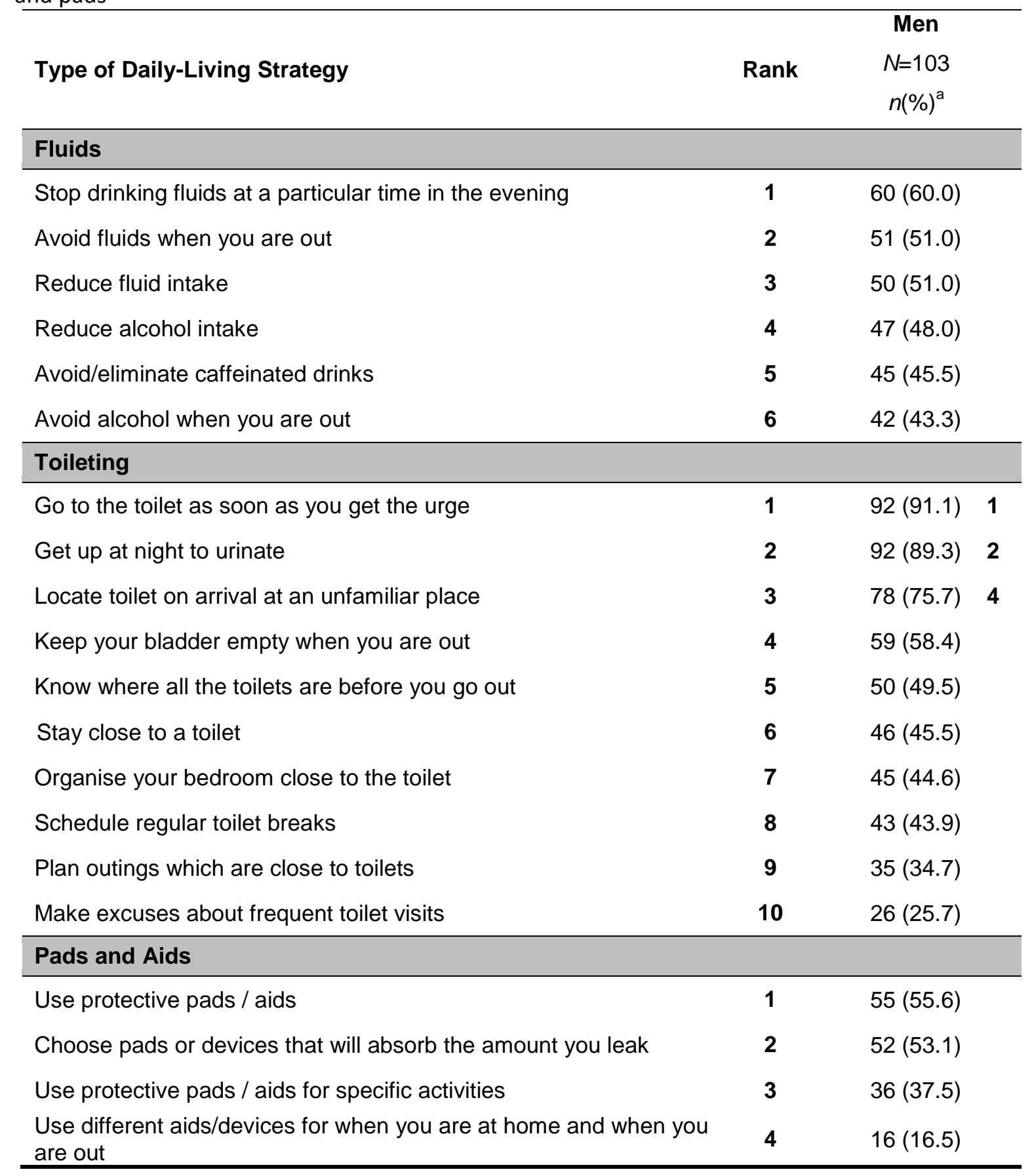


Table 3: Ranked daily-living strategies for managing urinary incontinence: Social and routines

\begin{tabular}{|c|c|c|c|}
\hline Type of Daily-Living Strategy & Rank & $\begin{array}{c}\text { Men } \\
N=103 \\
n(\%)^{\mathrm{a}}\end{array}$ & \\
\hline \multicolumn{4}{|l|}{ Social } \\
\hline Make managing leaking a normal part of everyday life & 1 & $74(74.0)$ & 5 \\
\hline Learn as much as you can about urinary incontinence & 2 & $71(70.3)$ & 6 \\
\hline Seek help from a health professional & 3 & $62(60.8)$ & 9 \\
\hline $\begin{array}{l}\text { Discuss your condition with close family and/or friends so that they } \\
\text { understand about accidents }\end{array}$ & 4 & $61(60.4)$ & 10 \\
\hline Use humour or positive thinking if an accident happens & 5 & $60(60.0)$ & \\
\hline Keep accidents a secret from close friends and family & 6 & $57(57.0)$ & \\
\hline Get help from close family and /or friends & 7 & $41(40.6)$ & \\
\hline Limit business and leisure travel & 8 & $35(36.1)$ & \\
\hline Avoid socialising, except with close family and friends & 9 & $28(28.3)$ & \\
\hline Avoid new relationships & 10 & $25(25.0)$ & \\
\hline \multicolumn{4}{|l|}{ Routines } \\
\hline Develop a routine to reduce the chance of leaking in public & 1 & $55(57.3)$ & \\
\hline Avoid situations where you can't get to a toilet easily & 2 & $56(55.4)$ & \\
\hline Take spare pads/aids with you wherever you go & 3 & $49(50.0)$ & \\
\hline Avoid situations where you are likely to leak & 4 & $47(47.0)$ & \\
\hline $\begin{array}{l}\text { Take an extra change of clothes and/or underwear when you go } \\
\text { out }\end{array}$ & 5 & $44(43.6)$ & \\
\hline $\begin{array}{l}\text { Stay home when you are more likely to leak eg. if sick or the } \\
\text { weather is cold }\end{array}$ & 6 & $35(35.0)$ & \\
\hline Stay at home & 7 & $26(26.5)$ & \\
\hline Change the timing or type of medication you take before you go out & 8 & $18(18.0)$ & \\
\hline
\end{tabular}


Table 4: Ranked daily-living strategies for managing urinary incontinence: Hygiene, body care, cleaning, physical activity and exercise

\begin{tabular}{|c|c|c|c|}
\hline Type of Daily-Living Strategy & Rank & $\begin{array}{c}\text { Men } \\
N=103 \\
n(\%)^{\mathrm{a}}\end{array}$ & \\
\hline Hygiene, body care and cleaning & & & \\
\hline Make sure your bowels stay regular & 1 & $79(79.0)$ & 3 \\
\hline Wash clothes and bedding regularly, whether soiled or not & 2 & $69(69.0)$ & 7 \\
\hline Purchase clothes and underwear that are easy to wash & 3 & $49(49.5)$ & \\
\hline Modify your diet & 4 & $46(46.9)$ & \\
\hline Have more showers than usual & 5 & $46(45.5)$ & \\
\hline Change pads frequently to avoid the smell of urine & 6 & $44(44.9)$ & \\
\hline Use deodorisers/perfume & 7 & $42(42.4)$ & \\
\hline $\begin{array}{l}\text { Wear clothes that conceal accidents eg. dark coloured, patterned, } \\
\text { skirts }\end{array}$ & 8 & $40(42.1)$ & \\
\hline Use creams to protect your skin & 9 & $31(31.0)$ & \\
\hline Make sure your home's floor coverings are easy to clean & 10.5 & $28(28.6)$ & \\
\hline Using protective aids for bedding & 10.5 & $28(28.6)$ & \\
\hline Carry a special bag for disposal of pads & 12 & $25(25.5)$ & \\
\hline Protect soft furnishings at home & 13 & $24(24.5)$ & \\
\hline Lose weight & 14.5 & $20(20.6)$ & \\
\hline Use skin wipes & 14.5 & $20(20.6)$ & \\
\hline \multicolumn{4}{|l|}{ Physical Activity \& Exercise } \\
\hline $\begin{array}{l}\text { Stop doing activities that make you leak eg. jogging, dancing, } \\
\text { standing for long periods } \\
\text { Plan activities for when you are less likely to lose control eg. after } \\
\text { passing urine, when rested }\end{array}$ & $\begin{array}{l}1 \\
2\end{array}$ & $\begin{array}{l}63(63.6) \\
40(40.4)\end{array}$ & 8 \\
\hline Urinate before and/or after sex & 3 & $37(38.1)$ & \\
\hline Use different positions for sex & 4 & $31(33.3)$ & \\
\hline $\begin{array}{l}\text { Tighten your pelvic floor muscles if you are in danger of leaking eg. } \\
\text { coughing, sneezing, lifting }\end{array}$ & 5 & $26(26.8)$ & \\
\hline Modify the activities you engage in eg. walking instead of jogging & 6 & $25(25.0)$ & \\
\hline Do pelvic floor exercises before particular occasions & 7 & $14(15.4)$ & \\
\hline Avoid having sexual intercourse or orgasm & 8 & $12(12.9)$ & \\
\hline
\end{tabular}

